\title{
La profesión legal y la tecnología en el Perú
}

\section{Óscar Montezuma Panez}

Abogado por la Pontificia Universidad Católica del Perú. Maestría en Derecho de Propiedad Intelectual y Regulación de Tecnologías de la Información por la Escuela de Derecho de la Universidad George Washington. Profesor de Derecho de Autor y Derecho de las Tecnologías de la Información en la Maestría de Derecho de la Competencia y Propiedad Intelectual de la Pontificia Universidad Católica del Perú. Presidente del Comité Latinoamericano de ItechLaw Association.

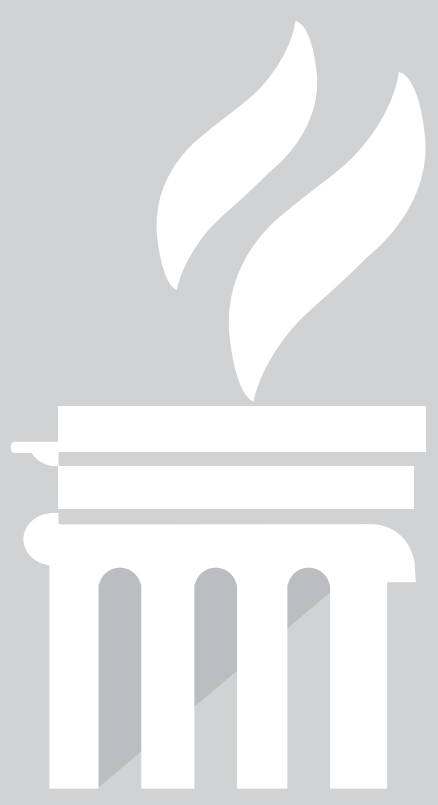




\title{
RESUMEN:
}

En la presente ocasión, ADVOCATUS tuvo la oportunidad de entrevistar a Óscar Montezuma Panez, abogado digital peruano especialista en Derecho de la Tecnología, propiedad intelectual, Derecho de la Competencia, negocios digitales e innovación legal. A través de las siguientes líneas nos ofrece sus opiniones sobre la profesión legal y su relación con la tecnología en el Perú, abordando temas como el uso de redes sociales y software, los formalismos del Derecho y reflexiones respecto a la innovación.

Palabras clave: Derecho, profesión legal, tecnología, redes sociales, innovación, formalismos.

\begin{abstract}
:
ADVOCATUS had the opportunity to interview Óscar Montezuma Panez, Peruvian digital lawyer specialized in Technology Law, intellectual property, Competition Law, digital businesses and legal innovation. In the following lines he offers his opinions about the legal profession and its relationship with technology in Peru, addressing issues such as the use of social media and software, the formalities of Law and reflections on innovation.

Keywords: Law, legal profession, technology, social media, innovation, formalities.
\end{abstract}

\section{1. ¿Qué retos enfrenta la profesión legal - respecto a la tecnología- actualmente?}

El principal reto es pensar que la innovación es comprar tecnología, es el principal problema que existe en la mente de algunos abogados. Y no solo abogados, en general asociar la palabra innovación a comprar tecnología o a qué tan techie eres. Cuando explotó la pandemia, muchas firmas de abogados sacaron comunicados diciendo: "Nosotros siempre estuvimos preparados, teníamos los mejores sistemas y las mejores plataformas". Sin embargo, a la par de eso comenzaron a salir memes y cosas que revelaban la cultura interna o la falta de ella de muchas firmas de abogados.

El principal reto que tiene el sector legal en general es asociar innovación con tecnología. En mi opinión, la innovación tiene que ver con la construcción de una cultura de trabajo y una cultura organizacional que en el modelo tradicional de las firmas de abogados no existe y no es una prioridad.

Específicamente hablando de tecnología, no hemos sido una profesión muy amigable con ella. Las firmas más grandes tienen sistemas más desarrollados, pero muchas tienen servidores localizados en la firma y tenían que ir a la firma para obtener la información que necesitaran o para conectarse por tener los accesos bloqueados. Hablar de tecnología en el mundo legal sigue siendo un tema muy retador, no es algo que se haya superado.

Por el COVID ya estamos obligados a trabajar de manera remota, hay una cantidad de matices. Estaba leyendo un artículo de los cinco niveles del trabajo remoto, siendo el uno el más básico y el cinco el más top. Me parece que el tres o el cuatro implicaba poder trabajar en un documento de manera colaborativa. Por ejemplo, que todos estemos juntos trabajando en un Google Docs al mismo tiempo editando un documento al mismo momento. Ese tipo de cosas no están muy difundidas en el mundo legal. Lo típico es que uno hace su Word, le hace un control de cambios, se lo pasa a otra persona, la otra persona le hace control de cambios y al final tienes el gestor de documentos o Word lleno de mil versiones del mismo documento. Hay todo un tema con la tecnología que los abogados recién estamos empezando a abrazar.

Hay dos tipos de tecnologías. La tecnología sostenible, que es aquella que ayuda a sostener la práctica legal tal cual. Por ejemplo, los software de horas, procesadores de textos, gestores de documentos. Por otro lado, la tecnología disruptiva, que es aquella en la que incluso sacas al abogado de la cadena. Por ejemplo, una solución tecnológica en la que la persona se acerca a una máquina dispensadora y compra un chocolate, hace lo mismo pero con un contrato. 
El tercer tema, que me parece que es el tercer gran reto, es cómo nos presentamos como abogados frente a los riesgos de la tecnología. Por ejemplo, en el caso de Panama Papers, hay un estudio de abogados que se ve afectado por una brecha de información gigantesca donde hay información confidencial protegida por el secreto profesional. Entonces creo que en la medida que seamos más digitales porque la realidad nos obliga a hacerlo, vamos a necesitar mayores medidas de seguridad para proteger el secreto profesional, que es una discusión que está bastante olvidada en el mundo legal.

\section{2. ¿Qué opina sobre la presencia de aboga- dos en redes sociales? Dados los prejui- cios sobre lo "informal" de las redes so- ciales y lo "formal" del Derecho.}

He visto cada vez más abogados en redes sociales. Hay un abogado en Ecuador que tiene una cuenta de TikTok y da consejos legales. Me pareció innovador el formato que utiliza, que además es limitado por un espacio de tiempo. En Instagram he visto a una abogada que es laboralista y fashion influencer y mezcla los dos temas. Sale posando con la ropa y las cosas que le mandan y al mismo tiempo también habla sobre Derecho Laboral. También está En Modo Legal de Melina Valle que ayudan a emprendedores y utilizan muchas figuras relacionadas con la música y el emprendimiento. Son formatos nuevos que buscan justamente mostrar contenidos legales de una forma más amigable.

Creo que es necesaria la presencia de abogados en redes sociales porque son formas de contribuir con la difusión de temas legales, pero es difícil por los prejuicios sobre lo informal y formal del Derecho. El abogado tradicionalmente, hablando de hace muchos años atrás, era el que publicaba su columna en Gestión, ese era el estándar. Pero luego viene la explosión de las redes sociales como Facebook y Twitter y dices: "¿Qué hago acá?". Creo que escribí un artículo en algún momento sobre el uso de redes sociales para abogados y al final mi conclusión fue que hay que estar, porque si no estás pierdes una oportunidad para posicionarte y difundir lo que sabes, y también te puedes perder de muchas cosas que se pueden estar hablando de ti. Pero lo principal es que una vez que tomas la decisión de estar en redes sociales, tienes que elegir bien tu estrategia y saber qué redes sociales vas a usar y cómo las vas a usar.

El gran error que veo en los abogados es que piensan que la red social es como un espacio para pegar tu newsletter que es un "Iadrillazo" en PDF que nadie entiende. Es dificilísimo de leer, es un "ladrillazo" de varias páginas que lo trepas y está colgado en Linkedln en Times New Roman $12-y$ si se puede más chica, mejor-, en un formato poco amigable y ahí está tu newsletter con todo el contenido que mandabas por correo electrónico, pero ahora lo pegas ahí, nada que ver. Hay toda una corriente de posicionamiento de contenidos que resaltan el cuánto yo sé. "Yo uso las redes sociales como abogado para demostrar cuánto yo sé" y ese no es el código de conversación en una red social. El código de conversación de la red social es conectar con la gente, hacer engagement. Es que tu contenido realmente le sirva a otra persona, conectes con la persona y así, la gente te empieza a seguir. No es para dar una charla magistral sobre cuánto sabe uno de acto jurídico o de alguno de esos temas porque a la gente no le interesa eso en esos espacios. Creo que si vas a estar presente en redes sociales, lo importante es que las utilices correctamente, conectado con que el contenido sea pensado para ayudar a otras personas, guiarlas sobre temas legales y no tener miedo de usar un lenguaje más aterrizado.

De hecho, uno de los grandes problemas que he encontrado en el mundo legal es el excesivo uso del formalismo en el lenguaje, en la vestimenta y en otras cosas, que hacen que pensemos que estamos banalizando el lenguaje o la profesión porque hablamos en simple. En mi opinión esto no es así. Discrepo de la forma de ver el Derecho acartonado y de hablar en difícil. Aprendemos a hablar en difícil, a vestirnos de una manera, a estar rígidos, y ello contribuye a nuestra presencia en redes sociales porque trasladamos esta rigidez a espacios que no la soportan.

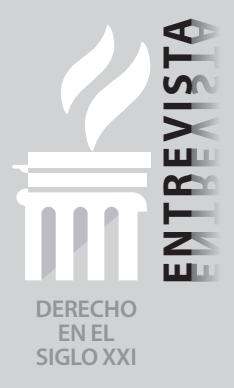


Algo importante que sí hay que tener en cuenta son las reglas de ética para utilizar redes sociales porque hay varios ejemplos de abogados que no se han medido y terminan divulgando información o comentando asuntos que está viendo la firma donde trabajan. Entonces, pueden terminar comprometiendo el secreto profesional si no siguen ciertas pautas. Yo personalmente soy "pro-uso" de estas herramientas de comunicación, lo cual no quita que debamos tener ciertos cuidados.

\section{3. ¿Considera que los "formalismos" - des- de la vestimenta hasta la forma de ha- blar- son esenciales para un abogado? ¿Se encuentran presentes en las firmas o abogados peruanos?}

No son esenciales $y$, de hecho, creo que van a ir desapareciendo. Por ejemplo, escribí un artículo sobre que "el hábito no hace al monje" y que en el tiempo, el uso de la corbata ha ido desapareciendo. Pero en el mundo legal sigue existiendo la rigidez y la idea que se debe vestir terno, y la forma de calmar la consciencia es no usar corbata los viernes, pero eso es como el premio de consuelo: "me siento menos formal porque no uso corbata el viernes". ¿Por qué no podríamos vestirnos como en una empresa? Los gemelos, los ternos mandados a hacer por sastre y las camisas con iniciales son parte de una especie de inducción al mundo formal de Suits.

Esa formalidad está plasmada no solo en la forma de vestirnos, sino también en la de hablar, por ejemplo, el "doctoreo". Recuerdo que participé en un evento hace unos años y se me acercó un chico, todavía estudiante, súper "encorbatado". Me decía: "Dr. Montezuma, yo quisiera decirle..." y le respondí que no me diga doctor, que soy Óscar y que conversemos relajados. Me quedé pensando en que si un chico que está en la universidad, tiene "veinti pocos" años y está saliendo al mundo laboral, y sigue replicando las prácticas de cuando yo era estudiante o practicante, entonces hay un problema serio en el sistema. No pueden haber pasado tantos años y que sigan las mismas prácticas en cuanto a la vestimenta. El chico un poco más y esta- ba ahorcado con la corbata y casi sin aire y todo nervioso intentando encontrar la mejor forma de "doctorearme". El lenguaje también está plagado de ese formalismo. Yo en la oficina solía hacer una purga mensual de los correos que enviaba la gente del equipo que más conectores leguleyos habían utilizado: "sin perjuicio de, estoy procediendo a enviar" y otras cosas innecesarias. Los anotaba en un papel y públicamente lo trituraba: "vamos a exterminar de nuestro lenguaje todos estos tecnicismos que no es que se nos ocurren, si no que nacen de la doctrina y todos los libros que leemos, y así aprendemos a hablar en difícil, y no nos permiten desarrollar mecanismos de comunicación asertiva".

Al final, ello termina distanciando al abogado de su cliente. Creo que hay un espacio en las nuevas generaciones, la de ustedes por ejemplo, para romper los moldes. Que el abogado sea una persona cercana y amigable, que te ayude a resolver problemas pero que no sea un personaje lleno de gemelos, de camisas, de sastres -en el caso de las mujeres los tacosque distancia de otras cosas y bloquea la innovación. Cuando una persona es tan rígida y resistente al cambio, también lo es con nuevas ideas que puedan llegar a influir en su trabajo y nos convierte en una profesión particular. Eso no implica que dejemos de utilizar tecnicismos propios de la profesión como al hablar del acto jurídico, no hay otra forma de decirlo, es el nombre que se le puso.

\section{Muchos clientes están acostumbrados a tener abogados que visten y hablan for- mal. ¿Les parece extraño cuando aboga- dos jóvenes les hablan coloquialmente?}

En el 2012 me lancé a emprender como abogado, y hasta el 2018, son seis años que me tomó "exorcizarme" — porque así le llamo- de todas estas prácticas. Es un exorcismo porque eso es en lo que te formaste. Yo me formé en ese mundo y recién Niubox se convierte en mi primer proyecto en el que logro romper completamente con esos moldes. Empezamos en un coworking porque dijimos que no vamos a tener una oficina pomposa ni la oficina de Suits. 
"Hay que erradicar por completo eso, eso se va, no existe". Y la onda o el look con el que andábamos era casual, no tenía que ser un requisito estar acartonado. Me acuerdo que un cliente me dejó frío porque llegó a la oficina y me felicitó por no recibirlo en terno y corbata. No sabía qué responderle o si decirle gracias. Me dijo: "qué chévere poder conversar en esta misma onda" porque se sentía identificado conmigo porque estábamos vestidos de una manera parecida. No venía este personaje inalcanzable a hablarle en difícil. Creo que, sobre todo, la generación de ustedes es la llamada a ser el fumigador para sacar del mundo legal la mayor cantidad de formalismos y cosas de ese tipo.

5. En el 2011, la International Bar Association-IBA realizó un estudio para evaluar la presencia y el rol del networking en redes sociales dentro de la profesión y la práctica legal a nivel mundial. El $80 \%$ de los encuestados declaró que era necesario adaptar los códigos y normas éticos-profesionales a las interacciones sociales en línea que afectan a la profesión y el ejercicio de la abogacía, ya que no pueden aplicarse adecuadamente en su forma actual. ¿Considera que es necesaria esta adaptación en el Perú?

Creo que hay que revisar las normas de ética de los colegios de abogados y hacer una revisión un poco más exhaustiva a esos temas. En cuanto a los aspectos éticos, los temas de conflicto de interés y anticorrupción, somos los especialistas en recomendar compliance o lavado de activos a otros, pero en el mundo legal es algo que todavía está un poco dejado de lado.

Concretamente en el caso de las redes sociales, si ven al final en los créditos del documento de la IBA aparece el Colegio de Abogados de Lima-CAL. El CAL participó en ese documento. Sin embargo, la actividad del CAL y de otros colegios profesionales es una actividad que aporta muy poco para las profesiones y la profesión del abogado en general. El tema de tener normas éticas sobre interacciones en línea sí puede ser interesante para ser retomado porque tiene que ver con que muchas veces utili- zamos las redes sociales sin darnos cuenta. He visto varios casos de gente que tiene agregada dentro de sus contactos a personas que ni conoce o por ejemplo, cuando un abogado está prohibido de agregar como contacto a un juez -y en Estados Unidos se ha visto mucho estos casos - porque puede generar alguna vinculación que afecte el debido proceso y que genere asociaciones que no vengan al caso afectando la neutralidad del juzgador. Existe una cantidad de reglas que están en el estudio de la IBA que son importantes para tener en cuenta y me parece que sería muy válido que se retome. Las firmas de abogado, por ejemplo, tienen políticas para que sus abogados usen o no redes sociales y cómo usarlas. Yo creo que, alineado con lo que respondí al inicio, hay que potenciar mucho más en el mundo legal el uso de las redes sociales, pero también hay que tener ese tipo de lineamientos y guías para que la gente lo pueda hacer de manera segura, tranquila y que no se viole el secreto profesional. En otros países, por ejemplo, autodenominarse experto o "likear" un comentario donde atacan al cliente del estudio puede traer problemas. ¿Hasta dónde llega nuestro lado personal con nuestro lado profesional? Son cosas en las que es importante tener algún tipo de guía. En redes sociales, un screenshot de lo que comenté antes te puede terminar anulando la carrera. Por ello creo que es importantísimo adaptar ese tipo de lineamientos a la realidad local.

\section{En algunos países - como China - se ha planteado la implementación de jueces robots en ciertos casos. ¿Considera que, en el futuro, la inteligencia artificial po- dría reemplazar ciertas funciones legales en el Perú?}

El tema de la inteligencia artificial y también el de otras tecnologías que están desarrollándose actualmente es que todavía hay mucho hype sobre ello. Creo que la gente ha empezado a ver mucho Black Mirror o The Social Dilemma y han empezado a "loquear". Entonces ahora es que "los robots nos van a quitar la chamba", y lo que yo primero diría es que hay que sentarnos a entender bien cuál es el alcance que está teniendo esta tecnología, y, 
qué es lo que efectivamente al día de hoy es real y se puede hacer.

Todavía creo que estamos muy lejos de poder reemplazar la justicia con software. Parto de la idea de que no conozco ningún software de inteligencia artificial que sea completamente autónomo, al final está hecho por un humano, y el humano tiene sesgos, entonces eso puede influir claramente en el diseño del software.

¿Creo que la inteligencia artificial podría ser un gran complemento para la administración de justicia? Sí. ¿Que vaya a reemplazar completamente a los jueces? Creo que estamos muy lejos de que algo así ocurra. Sobre todo, creo que es importante entender bien qué cosa es lo que al día de hoy es posible, fácticamente, de hacer con la tecnología. Porque hay mucha ciencia ficción sobre el tema y eso nos genera una serie de expectativas en la mente de cosas que pueden ser irreales o lejanas. Y como digo, mucho ver Black Mirror o esas series es un buen ejercicio de reflexión sobre los usos de la tecnología y hasta dónde puede llegar, pero también es cierto que fomentan el "tecno-pánico", fo- mentan el miedo. Hay muchos cuestionamientos que le han hecho al documental The Social Dilemma porque hay partes en las que es poco objetivo. No quiero extenderme hablando del tema porque no viene al caso, pero sí quiero hablar de que hay que ser conscientes de qué es lo que se puede hacer al día de hoy con la tecnología, estudiarla bien. Si a ustedes les interesa el tema, y eso es algo que se los digo porque me han preguntado mucho últimamente: "Oye, ¿en qué curso de tecnología me meto?", yo les digo: "¿Sabes qué? Más Derecho del que ustedes ya saben, no les van a enseñar en un curso de Derecho de Tecnología". Entonces, si pueden meterse a un curso, de los que ahora hay muchos y gratuitos, sobre cómo funciona el blockchain, la inteligencia artificial, el data analytics, y entenderlo y ver la aplicación real, ustedes van a poder aplicar el Derecho a esa tecnología de una manera mucho más fácil. Más van a aprender haciendo eso que estudiando un curso de Derecho de Tecnología o alguno relacionado. Entonces este es un poco el reto que tenemos ahora los nuevos abogados que queremos entrar a la especialidad del Derecho de la Tecnología. 